\title{
Consensus mounts for national drug formulary
}

$\mathrm{W}$

ith hearings on national pharmacare underway in Parliament, a diverse group of experts at a recent symposium on pharmaceutical policies endorsed the idea of a federally coordinated, national formulary of recommended drugs to guide Canada's multitude of public and private insurance plans.

"Exploring the need for a national formulary" was part of federal Health Minister Jane Philpott's mandate in November 2015. In late April, seven academics and physicians strongly endorsed it during Parliamentary hearings.

At the Pharma Symposium Canada: Finding the Path to an Accessible and Sustainable Market, in Toronto May 2 and 3 , the national formulary concept drew support from a broader range of people. These included a free marketoriented economic think tank, patients' associations, federal drug review agencies and the pharmaceutical industry.

Perhaps most surprising was the support from Colin Busby, associate director of research for Toronto-based CD Howe Institute, a think tank whose mandate is to foster economically sound public policies. In a symposium panel on the merits of a national pharmacare program, Busby warned that such a program "would not be wise," but warmly endorsed the idea of Ottawa developing a "model formulary" similar to New Zealand's. He said a federal formulary should not be expected to replace the dozens of public and private formularies already in use across Canada. Instead, there should be competition between existing formularies and the new federal one. This would help payers inform and refine decisions about which drugs should be covered by public and private insurers, Busby suggested.

Busby praised the federal government's decision to allow the independent pan-Canadian Pharmaceutical Alliance (pCPA) to negotiate on behalf

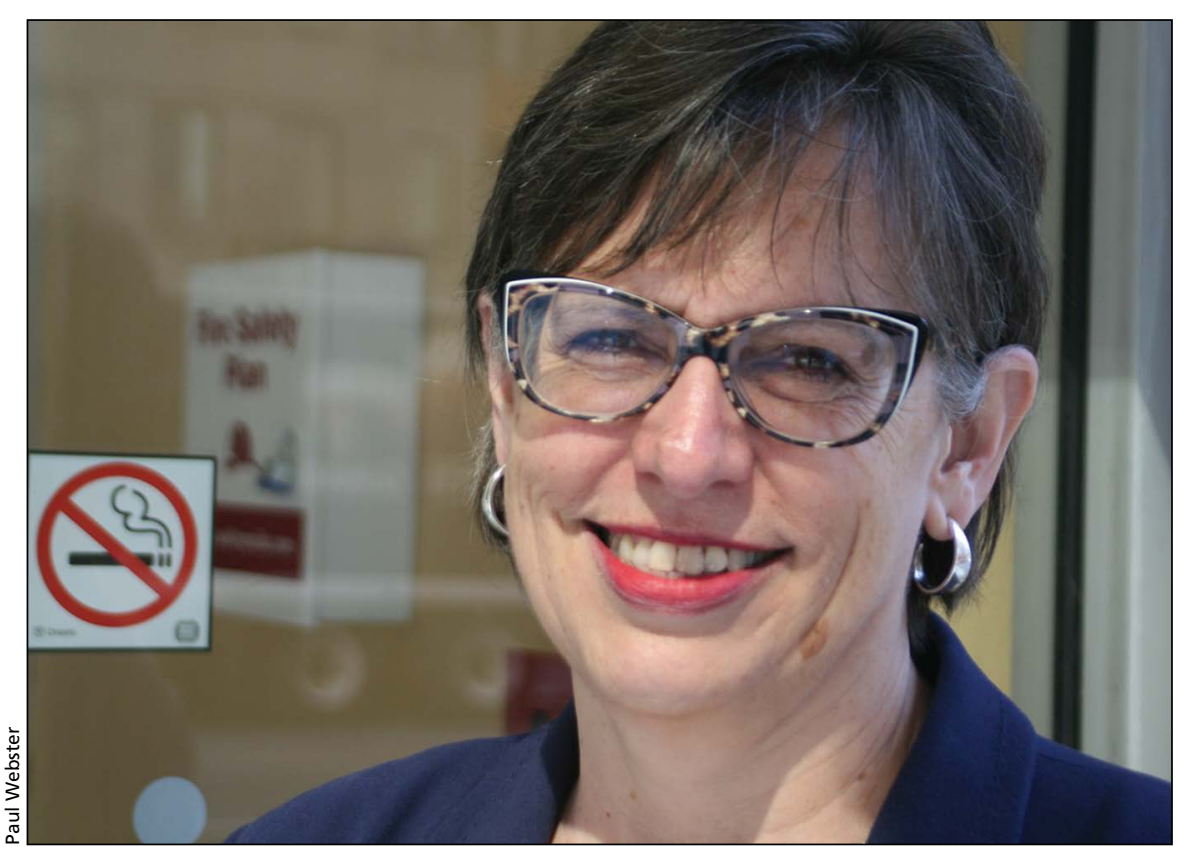

Dr. Jan Hux of the Canadian Diabetes Society endorsed a public formulary, but cautioned that it shouldn't compromise innovation and choice.

of provinces and territories to get lower-priced brand name and generic drugs through bulk purchasing for drug purchasing programs for certain groups. These include military and RCMP employees, First Nations and Inuit people. The pCPA is estimated to have saved $\$ 490$ million since 2010.

In a panel discussion on drug-marketing regulations, Alain Boisvert, vice president of Market Access and Public Affairs for Bristol-Myers Squibb Canada, said Ottawa has already "come a long way towards national pharmacare" thanks to its support for both the pCPA and the Canadian Agency for Drugs and Technologies in Health (CADTH), another independent agency, created in 1989 by federal, provincial and territorial governments to coordinate assessments of drugs and health technologies.

"That's $80 \%$ already of a national pharmacare system," Boisvert said. "The other $20 \%$ is the existence of the provincial formularies."If the provin- cial formularies can be standardized within a national framework, Boisvert added, "it's no longer a patchwork of autonomous drug plans."

Representatives from two patients' groups who spoke at the symposium also supported federal leadership in developing a national formulary.

But both Dr. Jan Hux, chief scientific advisor for the Canadian Diabetes Society, and Louise Binder, health policy consultant at the Cancer Survivors Network, warned that a national formulary should not be based on the demands of the most cash-strapped governments. "A model national formulary should not be produced at the cost of innovation and choice," Hux said.

Representatives from the pCPA and CADTH at the Toronto symposium said their organizations would be willing to consider taking roles in developing a national formulary. - Paul Webster, Toronto, Ont.

CMAJ 2016. DOI:10.1503/cmaj.109-528 